\title{
VIEWPOINT: TELECOMMUNICATIONS AND INTERNET BROADBAND POLICY: SORTING OUT THE PIECES FOR TELEREHABILITATION
}

\author{
KATHERINE D. SEELMAN, PH.D. \\ DEPARTMENT OF REHABILITATION SCIENCE AND TECHNOLOGY, UNIVERSITY OF PITTSBURGH
}

ABSTRACT

Technological change is accelerating and with it regulatory upheaval. Most of us agree that providing universal telecommunication services to all our citizens is a worthy ideal. Nonetheless, many of us do not agree that regulation should be the means to make broadband Internet services widely available. This Viewpoint begins sorting out pieces of the emerging United States, regulatory and policy puzzle for broadband Internet with an eye to the interests of telerehabilitation providers and consumers. Just how might changes in legal authority, regulation and agency jurisdictions impact us?

\section{BACKGROUND}

The "tele" part of telerehabilitation crosscuts a number of policy and regulatory areas -- so a little background information on the landscape can be helpful. Modern telecommunications regulation has been about balancing the needs for innovation, fair competition and a level playing field of availability, affordability and accessibility for all Americans, (i.e., universal service). The Federal Communications Commission (FCC) today implements the mandate for universal service set forth in the Telecommunications Act of 1996 [1]. The FCC has set in motion universal service policies that ensure all Americans, including low-income consumers, those with disabilities and those who live in rural, insular, high cost areas, have affordable service. The FCC will help to connect eligible schools, libraries, and rural health care providers to the global telecommunications network. The FCC has responsibility for implementing Section 255 of the Act. Section 255 requires that telecommunication service providers and equipment manufacturers make their products accessible, if readily achievable. While the FCC does not regulate Section 508 of the Rehabilitation Act as amended in 1998, it, like other federal agencies, may not procure, develop, use or maintain electronic or information technology that is inaccessible to people with disabilities, unless this creates an undue burden. So what has changed?

The FCC's legal authority to regulate the Internet has been called into question recently by industry and the courts. At the same time, rapid technological change has led to technological convergence, especially that most dramatic convergence, the Internet. The Internet delivers the content of plain old telephone service along with video, data and so much more. Internet broadband delivers key privileges, rights and services of e-government, e-health, e-commerce, and e-education. But broadband Internet is not a level playing field. Availability, accessibility and affordability are determined by factors such as socioeconomic status, location and disability. Technological convergence, globalization and other factors are also driving change in Federal agency responsibility so that regulatory boundaries have become porous. As described below, agencies such as the FCC are teaming up with other agencies to shoulder overlapping responsibilities such as transmission and health services; new agencies are emerging. Health information technology (HIT) and the emergence of sectorspecific telecommunication domains-such as healthadd another layer of complexity.

\section{FEDERAL COMMUNICATIONS COMMISSION (FCC)}

For over 75 years, the FCC has held sway in decisions about availability of communication service for all our people. The Commission has done so largely by regulating telecommunications. In March 2010 the FCC released its futuristic National Broadband Plan [2]. The Plan contains a health section that envisions wide availability of affordable Broadband. The Plan also addresses problems of availability, affordability and accessibility for unserved and underserved populations such as those living in rural areas or having disabilities [3]. In April 2010, a court of appeals decision cast a dark shadow, if not erecting a roadblock to FCC's ability to exert legal authority over broadband Internet. In Comcast vs. FCC the court called into question FCC's authority to regulate the Internet [4]. The FCC is now moving 
forward with a framework to restore its role [5]. It intends to proceed with limited regulation of the transmission component of broadband Internet, but not the content [6]. Health providers and consumers await further clarity about FCC's authority to implement its Plan.

As noted earlier, FCC regulatory activity is also beginning to harmonize with that of other regulatory agencies such as the Food and Drug Administration (FDA). The FCC's Broadband Plan envisions advancing broadband communications to help foster the use of remote medical devices to reduce costs and improve care. The FDA regulates medical devices; therefore, these once distinct regulatory agencies will increasingly collaborate.

\section{FEDERAL FOOD AND DRUG ADMINISTRATION (FDA)}

Because medical systems are converging with communications, the FCC and the FDA are meeting so as to take a teamwork approach to telemedicine [7]. Collectively, they will identify the challenges and risks posed by the proliferation of new sophisticated medical implants and other devices that utilize radio communications to effectuate their function, as well as challenges and risks posed by the development and integration of broadband communications technology with healthcare devices and applications.

\section{OFFICE OF NATIONAL COORDINATOR FOR HEALTH INFORMATION (ONC-HIT), U.S. DEPARTMENT OF HEALTH AND HUMAN SERVICES (HHS)}

ONC-HIT is another piece of the emerging policy and regulatory puzzle. In its role as policymaker and coordinator, ONC-HIT is important to telerehabilitation [8]. A relatively new unit created by US Executive Order in 2004, it was written into legislation by the HITECH Act of 2009. The unit's responsibilities include policy coordination and promotion, and development of a national health information technology (HIT) infrastructure. This infrastructure is called for by the American Recovery and Reinvestment Act 2009 (ARRA) [9].

The government has tools in addition to regulation, such as grants and other incentives, to spur development of broadband technology. ARRA includes approximately a \$19.5 billion investment in HIT. The ARRA allocated \$6 billion in funding for broadband deployment. The National Telecommunications and Information Administration (NTIA), U.S. Department of Agriculture's (USDA) Office of Rural Development, and the FCC are working together to implement the broadband initiatives funded by the ARRA. The Act initiatives include the new Broadband Technology Opportunities Program, the new Rural Development Broadband Program, and the development of a National Broadband Plan. Over $\$ 2$ billion in grants are administered by the NTIA for "unserved" and "underserved" areas of the country. The Broadband Initiatives are intended to accelerate broadband deployment in unserved, underserved, and rural areas and to strategic institutions that are likely to create jobs or provide significant public benefits. The FCC has the responsibility to identify unserved and underserved areas.

Other Federal departments, such as Veterans Affairs, apply section 508 of the Rehabilitation Act to health records such as electronic health records (EHR) and personal health records (PHR). The ONC is also evincing interest in HIT accessibility. It recently issued a notice of interim standards for HIT [10]. The notice requested public comment on the accessibility issue and received over a dozen comments advocating for accessibility of HIT. If HHS should choose to apply HIT standards to accessibility in the future, it would extend HIT accessibility standards to entities outside the federal sector. The disability community supports applying the HIT certification program in evaluating HIT for accessibility [11]. Although HIT certification is voluntary, the impact of folding accessibility into HIT standards could be significant in terms of helping people with disabilities across the United States. The ONC-HIT may also choose to assign staff for managing HIT accessibility and disability issues.

\section{U.S. ACCESS BOARD}

The Access Board is an independent agency that promulgates standards and guidelines on information and communications technology (ICT) under Section 508 of the Rehabilitation Act and Section 255 of the Telecommunications Act. Health Information Technology (HIT) is considered a subset of ICT. HIT includes electronic content, such as websites, documents, and software. HIT can include ICT such as videos, information kiosks, hand-held PDA devices, and telecommunications products. The Access Board convened an HHS panel to speak at a recent meeting of its Board. Panelists included the ONC-HIT, Agency for Healthcare Research and Quality, Office of Minority Health, and Office of Civil Rights.

The Access Board received new authority under the Patient Protection and Affordable Care Act 2010 to 
issue standards for accessibility of medical diagnostic equipment. Medical diagnostic equipment includes examination tables and chairs, weight scales, x-ray machines and other radiological equipment, and mammography equipment. This new authority brings the Access Board, the FCC and the FDA into common regulatory territory.

\section{PIECES OF THE PUZZLE AND TELEREHABILITATION}

Using a wide range of tools, including its budgetary authority, US President Barak Obama's administration has signaled a strong commitment to universal Broadband service and to the advancement of HIT. Telrehabilitation should find its place at the various tables, especially in grants and in interaction with the various agencies involved. The FCC is executing its regulatory role to meet the nation's responsibilities to deliver broadband to the public. At least one company, Comcast, has pushed back through the courts resulting in a judgment that put into question the FCC's legal authority to regulate the Internet. Nonetheless, the FCC has longstanding authority to regulate transmission and will continue to be an important player. Coordination among the various agencies appears unusually smooth, especially in the advancement of HIT, because of the ONC-HIT. Telerehabilitation leaders should monitor ONC-HIT's activities and become involved when opportunities occur. The disability community and its friends have numerous legal avenues to advocate for access to broadband, HIT and telemedicine. The telerehabilitation research community should be resourceful in the development of useable and accessible products and services.

\section{REFERENCES}

[1] Commission Implements Telecom Act's' Universal Service Provisions. http://www.fcc.gov/Bureaus/ Common_Carrier/News_Releases/1997/nrcc7032.html Accessed June 2010.

[2] National Broadband Plan Connecting America. http:// www.broadband.gov/ Accessed June 2010.

[3] Coalition of Organizations for Accessible Technology. http://www.coataccess.org Accessed June 2010.

[4] U.S. Court of Appeals, District of Columbia Circuit. http://pacer.cadc.uscourts.gov/common/ opinions/201004/08-1291-1238302.pdf. Accessed June 2010.

[5] The Third Way: A Narrowly Tailored Broadband Framework. http://www.broadband.gov/the-third-waynarrowly-tailored-broadband-framework-chairmanjulius-genachowski.html. Accessed June 2010.

[6] F.C.C. Moves to Expand Role in Broadband. New York Times, June 18, 2010, B2.

[7] Converged Communications and Health Care Devices Impact on Regulation. http://www.tradingmarkets.com/ news/stock-alert/mdsy_converged-communicationsand-health-care-devices-impact-on-regulation-publicmeeting-request-for-c-990471.html Accessed June 2010.

[8] Office of the National Coordinator of Health Information Technology. http://searchhealthit.techtarget.com/ definition/ONC Accessed June 2010.

[9] Blumenthal Named National Coordinator for Health Information Technology http://harvardscience.harvard. edu/medicine-health/articles/blumenthal-namednational-coordinator-health-information-technology Accessed June 2010.

[10] Health Information Technology Standards and Certifications. http://healthit.hhs.gov/portal/server. pt?open $=512 \&$ objlD $=1153 \&$ mode $=2$. Accessed June 2010.

[11] Personal communication with David Basquith, Access Board June 2010. 
